\title{
SOLID WASTE LABORATORY SAMPLES HOMOGENEITY INFLUENCE ON ANALYTICAL DETERMINATION
}

\author{
Mona Barbu $^{1}$, Agnes Serbanescu', Ileana Nicolescu ${ }^{1}$, Elena Bucur ${ }^{1}$ \\ ${ }^{1}$ National Research and Development Institute for Industrial Ecology-INCD ECOIND, \\ 71-73, Drumul Podul Dambovitei Street, 06052, Bucharest, Romania, poluare.aer@incdecoind.ro
}

\begin{abstract}
The paper presents the influence of solid waste laboratory samples homogeneity on the determinations quality of calorific value and carbon content.

Laboratory tests were conducted for a sample of mixed solid wastes (biomass, textile, plastic). The waste laboratory sample was prepared for physico-chemical characterisation by using basic methods, mass and particle size-reduction of components. Particle size-reduction of components was carried out using two laboratory mills: Retsch Rotor Beater Mill SR 300, and Retsch Vibratory Disc Mill RS 200. Laboratory sample was prepared in two versions. In the first version (V1) particles size reduction took place by passing a $2 \mathrm{~mm}$ sieve through the rotor beater mill Retsch SR 300 . The plastic component of the waste was not fully integrated into the sample. In the second version (V2) the waste sample obtained in the first version was first pulverized in the Retsch Vibratory Mill RS 200, followed by a comminution of the particles to diameters passing a $0,5 \mathrm{~mm}$ sieve through the Rotor Beater Mill Retsch SR 300. In the second version the sample was visibly homogeneous.

Laboratory sample homogeneity influence was highlighted by determining calorific value and carbon content of the waste sample prepared in the two versions.

Following laboratory tests the results for carbon content and calorific value were within the repeatability limits imposed by the standardized methods for the second laboratory sample version.
\end{abstract}

Keywords: laboratory mill, samples homogeneity, solid waste, waste composition

\section{Introduction}

The EU approach to waste management is based on three principles: waste prevention, recycling and reuse and final disposal of waste. The final disposal of waste must be made in a safe manner for the environment and human health, with a strict monitoring program [1].

If the waste recycling and reuse is not feasible, the energy recovery, is considered by the European Commission as one of the sustainable waste management options in order to reduce the amount of hazardous stored waste [2].

One of the strategic objectives regarding the hazardous waste management is the energy recovery from this waste by promoting the energy recovery in cement kilns, minimizing their impact on human health and on the environment.

EU environmental standards regulated the emissions limit values for waste incineration and coincineration plants, and also require energy efficiency thresholds [3].

The conversion of municipal waste into refuse derived fuel, the so-called solid recovered fuels (SRF) and their incineration has become a current option as an alternative to classic fuels. 
Solid recovered fuels cover a wide range of waste materials which have been processed to fulfill guideline, regulatory or industry specifications mainly to achieve a high calorific value. Solid recovered fuels include residues from municipal solid waste recycling, industrial/trade waste, sewage sludge, industrial hazardous waste, biomass waste, etc [4].

Solid recovered fuels (SRF) must meet the requirements for classification and specifications laid down in the SR EN15359: 2012 "Fuels in recovery. Specifications and classes " standard.

SRF's classification system is based on three important characteristics mentioned as the main characteristics of SRF: an economical characteristic, represented by net calorific value, a technique characteristic, represented by the chlorine content and an environment characteristic represented by mercury content [4].

Knowing the composition of municipal waste is of great importance for an efficient operation of a "Waste-to-energy" plant. Waste constituents have different energy value and may cause various problems in the operation of such a plant [5].

The paper presents approaches for obtaining a representative laboratory sample for a mixed solid waste sample, and their homogeneity influence on laboratory tests.

\section{Materials and Methods}

\subsection{Laboratory sample preparation}

The article presents the research conducted on a sample of a heterogeneous solid waste, a mixed briquette shown in Figure 1, composed of a mixture of biomass, textile and plastic.

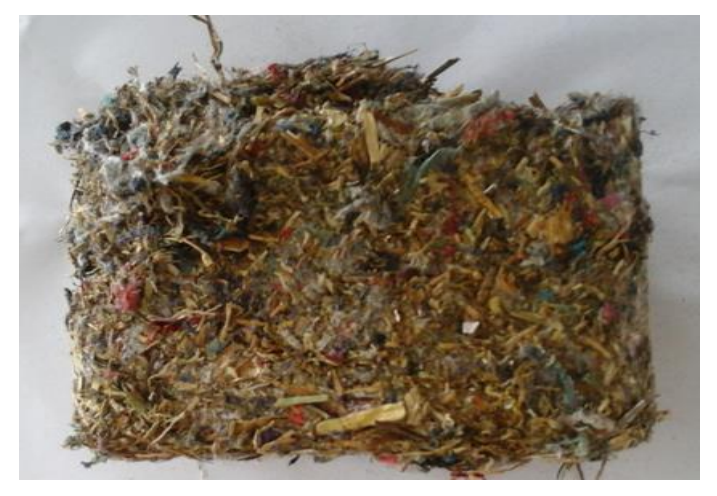

Figure1: Mixed briquette

Obtaining a representative laboratory sample is a complex process that must take into account a number of factors such as sample type, sample components state of aggregation, the type and number of laboratory analyzes that have to be realized.

The laboratory sample must meet certain conditions in the same time: to be representative, cross contamination prevention, the particle size must be in accordance with the requirements of the method.

The influence of laboratory samples homogeneity on the analyses results was performed by determining the gross calorific value and carbon content.

The statistical evaluation of the laboratory analysis results was done by calculating the mean value, the standard deviation and the relative standard deviation of repeatability, and the repeatability. The data were compared with the analysis methods requirements. 


\section{Results and Discussion}

\subsection{Laboratory samples obtaining}

A representative laboratory sample for the mixed briquette was achieved by using basic methods: homogenization, sample division and components size reduction [6].

The particles sizes reduction for the mixed briquette components was carried out using two laboratory mills: Retsch Vibratory Disc Mill RS 200 (Figure2), and Retsch Rotor Beater Mill SR 300 (Figure 3).

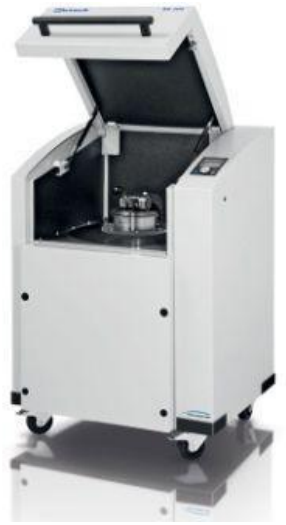

Figure 2: Retsch Vibratory

Disc Mill RS 200

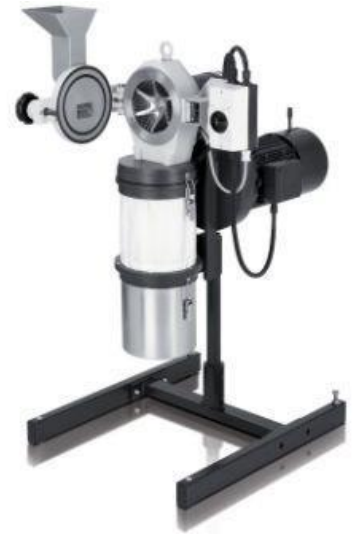

Figure: 3 Retsch Rotor Beater Mill SR 300

The standardized methods for wastes samples stipulate for moisture content, ash content and calorific value determination, the particles size below $1 \mathrm{~mm}$, and for carbon content determination, between $0.2 \mathrm{~mm}-0.5 \mathrm{~mm}$.

The particles sizes reduction for the mixed briquette was achieved by using first the Retsch Rotor Beater Mill SR 300 passing a $2 \mathrm{~mm}$ sieve, followed by the sample division. For this first laboratory sample version (V1) preparation, the plastic component of the waste was not fully integrated into the sample Figure 4.

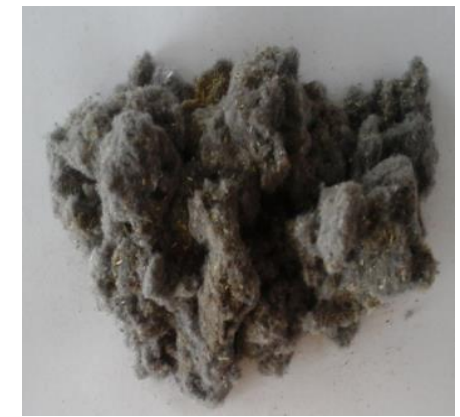

Figure 4: Mixte briquette laboratory sample version $1(\mathrm{~V} 1)$

In the second version of laboratory sample preparation (V2) the waste sample obtained in the first version was first pulverized in the Retsch Vibratory Mill RS 200, followed by a particles size reduction to diameters passing a $0,5 \mathrm{~mm}$ sieve through the Rotor Beater Mill Retsch SR 300. In the second version the sample was visibly homogeneous Figure 5. 


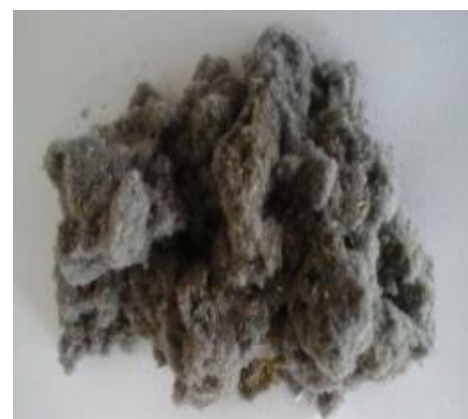

Figure 5: Mixte briquette laboratory sample version $2(\mathrm{~V} 2)$

\subsection{Laboratory sample homogeneity verification}

Laboratory sample homogeneity verification was done by statistical analysis of the results obtained for the determination of gross calorific value and carbon content for the two versions of laboratory samples. The obtained results were compared with the standard methods requirements.

Gross calorific value was determined using an isoperibol Parr 6200 calorimeter. The determinations were done on six replicates for each of the two versions of mixte briquette laboratory sample, according to the standard method SR EN 15400:2011. The samples weight was approximately $0.5 \mathrm{~g}$. For the analysis the samples were mixed with benzoic acid. Results are expressed as MJ/kg in dry weight basis. They are presented in Table 1 and in Figure 6a.

Carbon content determination in the laboratory samples was conducted in 6 replicates, using elemental analysis apparatus Thermo Fisher FLASH-type EA1112 CHNS, according to SR EN 15407: 2011. Results are expressed as percent in dry weight basis. The results are presented in Table 1 and in Figure 6 b.

The statistical evaluation of the results was done by calculating the mean value, the standard deviation and the relative standard deviation of repeatability, the limit of repeatability, and the repeatability coefficient of variation. The obtained data (Table 1) were compared with the analysis methods requirements.

Table1: Laboratory analysis results for the mixte briquette sample prepared in two versions

\begin{tabular}{|c|c|}
\hline \multicolumn{2}{|c|}{$\begin{array}{l}\text { Replicate/ } \\
\text { The performance parameters }\end{array}$} \\
\hline & \\
\hline $\begin{array}{l}\text { Repeatability } \\
\text { standard } \\
\text { deviation }\left(\mathrm{s}_{\mathrm{r}}\right) \\
\text { Repeatability }\end{array}$ & $\begin{array}{l}\text { samples } \\
\text { SR EN } \\
\text { 15400:2011 } \\
\text { samples }\end{array}$ \\
\hline $\begin{array}{l}\text { limit, } \mathrm{r}(\mathrm{r}=2.8 \\
\left.\mathrm{x} \mathrm{s}_{\mathrm{r}}\right) \\
\text { Coefficient of } \\
\text { the variation of } \\
\text { the } \\
\text { repeatability, } \\
\mathrm{CV}_{\mathrm{r}}, \%\end{array}$ & $\begin{array}{l}\text { SR EN } \\
\text { 15400:2011 } \\
\text { samples } \\
\text { SR EN } \\
\text { 15407:2011 }\end{array}$ \\
\hline
\end{tabular}

Gross calorific value at dry basis $\mathrm{MJ} / \mathrm{kg}$

\section{$\mathrm{V} 1$}

18.42

18.71

17.18

17.01

17.54

16.76

17.60

0.79

2.22

4.5

\section{$\mathrm{V} 2$}

18.00

18.08

18.51

18.23

18.08

18.26

18.19

0.19

0.27

0.52

0.76
Carbon content at dry basis

$\%$

$\begin{array}{cc}\text { V 1 } & \text { V 2 } \\ 47.05 & 47.81 \\ 49.80 & 48.07 \\ 43.78 & 48.46 \\ 46.47 & 47.45 \\ 43.49 & 47.26 \\ 45.35 & 49.24 \\ 45.99 & 48.05 \\ 2.34 & 0.73\end{array}$

1.63

$6.55 \quad 2.04$

5.09

1.51 


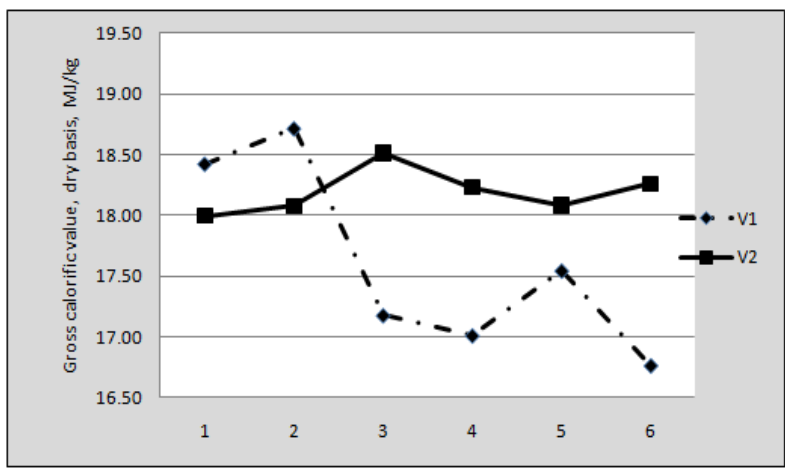

Figure 6 a: Gross calorific value determination, at dry basis, for the laboratory samples prepared in two versions

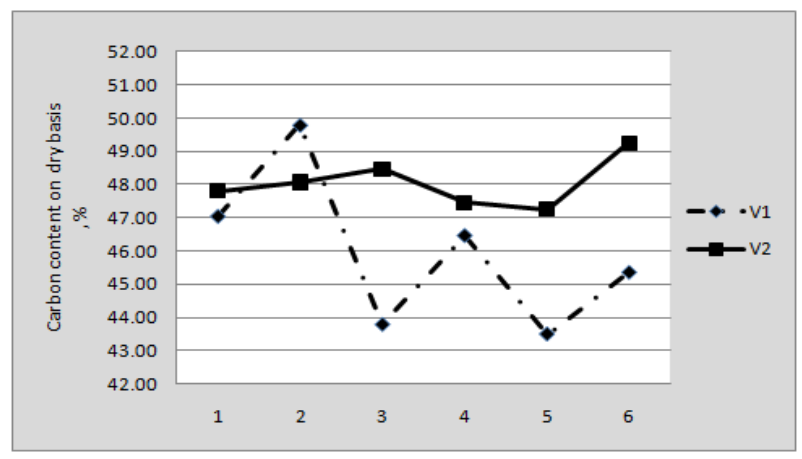

Figure 6b: Carbon content determination, at dry basis, for the laboratory samples prepared in two versions

The meam value of the results obtained for the determination of gross calorific value for the two versions of laboratory samples (Table 1) shows a difference of about $3 \%$. The repeatability standard deviation ( $\mathrm{sr}$ ) calculated for the results obtained for version 1(V1) is almost 4 times higher than for laboratory sample version 2 (V2). The results obtained for laboratory sample version 2 correspond the standard method performance requirements. From the statistical analysis of the results obtained for calorific value for the laboratory samples was highlighted that only the laboratory sample version 2 is homogeneous.

The results obtained for the determination of carbon content (Table 1), revealed a difference of approx. $5 \%$ between the average results for the two versions of laboratory samples. The repeatability standard deviation calculated for the laboratory sample version 1 was about three times greater than for laboratory sample version 2 . The results obtained for the laboratory sample version 1 does not correspond the standard method performance requirements for repeatability standard deviation and for the repeatability coefficient of variation. According to the statistical analysis of the results obtained for carbon content for the laboratory samples only the laboratory sample version 2 is homogeneous.

\section{Conclusions}

The correct characterization of solid waste has implications in waste management activities, in the safe operation of combustion installations and in carbon dioxide emissions report.

Representative laboratory sample preparation from solid waste is a difficult but also an important task for characterization due to their heterogeneity.

Laboratory sample preparation involves a sequence of operations like repeated particle-size reduction, mixing, and mass reduction until a sufficiently small but representative sample was obtained for chemical analysis.

The degree of homogeneity of the laboratory samples prepared from a mixed solid waste was established by the determination of gross calorific value and carbon content, and statistical evaluation of results. 


\section{Acknowledgements}

The mills used for laboratory sample preparation were procured under the project

"Centre for Advanced Interdisciplinary Research for Environment and Industry" project financed by the European Regional Development Fund within the Sectoral Operational Programme "Increase of Economic Competitiveness" "Investing for your future".

\section{References}

[1] http://www.mmediu.ro/beta/domenii/gestionarea-deseurilor/

[2] Decision no. 870/2013 approving the National Strategy on Waste Management 2014-2020

[3] Directive 2010/75 / EU transposed by Law 278/2013 on industrial emissions

[4] SR EN 15359:2012- Solid recovered fuels. Specifications and classes

[5] Factories such "Waste-to-energy" presentation. Prepared by S.C. Control Point S.R.L.

[6] SR EN 15443 Solid recovered fuels. Methods for the preparation of the laboratory sample 